\title{
Country-wide Survey on Covid-19 Preparedness of Medical Clinics of the Government Sector Healthcare Institutions
}

\author{
Vindya Kumarapeli ", Sinha De Silva**, Dhanushka Abeygunathilaka*, Nimani de Lanerolle* \\ Casthuri Kandasamy*, Uthpala Muhandiram*, Chithramali Rodrigo* \\ * Directorate of Non-Communicable Diseases, Ministry of Health, Sri Lanka \\ ** Postgraduate Institute of Medicine, University of Colombo, Sri Lanka \\ DOI: 10.29322/IJSRP.11.06.2021.p11487 \\ http://dx.doi.org/10.29322/IJSRP.11.06.2021.p11487
}

\begin{abstract}
NCDs were estimated to account for $83 \%$ of the total deaths in Sri Lanka in the year 2016. Continuing regular health services for patients with NCDs, amidst the COVID-19 pandemic, is a challenge. Ministry of Health has taken steps to provide guidance and training to continue services of medical clinics in government Healthcare institutions (HI). The aim of the study was to determine the Covid-19 preparedness of medical clinics in government sector HI to provide NCD services. A descriptive crosssectional study was carried out involving $682 \mathrm{HI}$ from all health districts of Sri Lanka, recruited by purposive sampling technique. A pretested self-administered questionnaire was administered to the heads of the institution (HOI) as a google form. The response rate was 97.4\%. Out of the respondents, $41.2 \%, 49.9 \%$, and $9.1 \%$ were primary, secondary, and tertiary HI respectively. More than $60 \%$ of the $\mathrm{HI}$ had updated patient databases, nearly $\mathbf{7 0 \%}$ had appointment systems to minimize overcrowding of patients, patient waiting areas with adequate distancing and ventilation, and drug dispensing mechanisms for a longer duration. Out of HIs 56.2\% had triage of patients on Covid19 symptoms before entering the medical clinic. Less than $20 \%$ of HIs had telemedicine facilities and $33.1 \%$ has digital blood pressure apparatus. Medical clinics of HIs in Sri Lanka have satisfactory preparedness with regard to the prevention of Covid-19.

Index terms- Covid-19, Medical Clinics, NCDs
\end{abstract}

\section{INTRODUCTION}

\section{BACKGROUND OF THE STUDY}

Sri Lanka has a high prevalence of NCDs that includes $24 \%$ of hypertensives and $8 \%$ of diabetics (World Health Organization 2015). The NCDs are estimated to contribute to nearly $83 \%$ of the deaths in the country in 2016 (World Health Organization 2020a). Therefore, NCDs are considered one of the leading public health problems compared to other health issues including communicable diseases.

Health System in Sri Lanka consists of the government and private sector. The government sector plays a vital role and bears the major share in the provision of health services since it is provided free of charge at the point of delivery. The diagnosed patients with NCDs are treated as out-patients, being followed up at medical clinics established at different levels of care that include primary, secondary, and tertiary.

Sri Lanka consists of 1,078 government healthcare institutes. Out of these government healthcare institutions that provide medical/NCD clinic services, which include two National Hospitals, 22 Teaching/General Hospitals, 81 Base Hospitals, 474 Divisional Hospitals and 499 Primary Medical Care Units (Ministry of Health 2020).

These clinics are manned by specialist medical officers and medical officers and each patient is given a follow-up plan and being reviewed at regular intervals. Patients with NCDs are given drugs for longer durations e.g. one month and instructions on how to use them (Ministry of Health 2018). In addition to this system, Health Lifestyle Centers with empaneled population are established throughout the country mainly in primary care institution for screening of NCDs in the community (Mallawaarachchi et al. 2016).

Since NCDs are considered a public health problem, a special national programme had been established in the Ministry of Health, Sri Lanka led by the Directorate of Non-Communicable Diseases. Its main objective is the prevention and control of NCD in the country and provides technical expertise and monitors the country's NCD status (Senaratne and Mendis 2019).

Sri Lanka consists of 26 Health districts and each district has a focal point i.e. Medical Officer-NCD (MO-NCD) to coordinate, monitor, and evaluate the NCD-related work within the district and liaise the center with the periphery in a manner to cover the whole country (Ministry of Health 2010).

Along with the other nations of the world, Sri Lanka is affected by the Covid-19 pandemic. Most of the sectors including health were affected by the pandemic. The focus of the health, as well as non-health sectors, was towards mitigation of the Covid-19 outbreak. Both existing human and materialistic resources in health sector were utilized for Covid-19 management and the attention towards non-Covid-19 related matters has deviated to a certain extent (World Health Organization 2021). This was a threatening situation even for the conduct of medical clinics for patients with NCD. The breakdown of services would have 
resulted in a severe surge of NCD-related morbidities and mortalities.

Several measures had been taken by Sri Lanka to prevent the spread of Covid-19. The majority of these measures were adherence to the DReAM concept which includes disinfection, maintenance of respiratory etiquette, adherence to aseptic techniques, and wearing of face mask (World Health Organization 2020b).

Groups of experts in public health in the Directorate of NCD of the Ministry of Health together with experts from the professional colleges prepared a guideline that gives directions on how to conduct the medical clinics amid the Covid-19 pandemic while adhering to the national policy on Covid-19 prevention. This guideline was validated by sending it to all the healthcare institutions under the signature of the Director General of Health Services. By considering the importance of uninterrupted functioning of medical clinics throughout the country, a specially targeted training of trainers (TOT) programme was organized. All the focal points of the districts i.e. MO-NCDs were trained and instructed to carry out training of all the heads of the institutions (HOI) in their respective districts.

After a lapse of two months duration, a countrywide survey was conducted covering all the districts of the country with the objective of assessing the Covid-19 preparedness of the medical clinics by Healthcare Institutions.

\section{II.METHOD}

A descriptive cross-sectional study was conducted from $15^{\text {th }}$ of April to $14^{\text {th }}$ of May 2021 involving all 26 health districts of Sri Lanka, among $700 \mathrm{HI}$ at primary, secondary, tertiary level by using purposive sampling technique. The questionnaire was prepared by group of experts in public health as well as other clinical fields. The face, content and consensual validity of the questionnaire was ensured by a panel of experts, and it was pretested prior to use in the proper sample. Data were collected by using a self-administered questionnaire which was administered via online platform. i.e., e mails, WhatsApp, Viber to the HOIs.

Two weeks duration was given to submit the responses, and all were given two reminders at the end of one week and 11 days since the commencement of the study to increase the response rate. In $10 \%$ of the sample was observed objectively by district focal points i.e. MO-NCD for validating the responses given by the participants.

The data was analyzed by using descriptive statistics and presented as numbers and percentages. Chi square test was applied to determine the association and odds ratio with $95 \%$ confidence interval to determine the strength of associations.

This study was conducted as an audit and a service need to obtain the status of Covid-19 preparedness of the medical clinics of every government healthcare institution. The consent of the HOI to data collection. The anonymity of the respondent was ensured.
Out of the recruited 700 government healthcare institutions 682 had responded with a response rate of $97.4 \%$.

The frequency distribution of healthcare intuition by districts are shown in Table 1.

Out of the respondents, $41.2 \%(n=281), 49.9 \%(n=340), 7.5 \%$ $(n=51)$ and $1.6 \%(n=10)$ were Primary Medical Care Units (PMCU), Divisional Hospitals (DH), Base Hospitals (BH) and General/Teaching Hospitals $(\mathrm{GH} / \mathrm{TH})$ respectively. Majority of the government healthcare institutions i.e., $56.3 \%(682 / 1,211)$ participated at this survey. The frequency distribution of healthcare institutions participated by health districts of Sri Lanka is shown in Table 1.

Table 1: Frequency distribution of healthcare institutions

\begin{tabular}{|c|c|c|c|c|c|}
\hline & $\begin{array}{l}\text { Number } \\
(\%)^{1} \text { of } \\
\text { PMCIs }\end{array}$ & $\begin{array}{c}\text { Number } \\
(\%) \text { of } \\
\text { DHs }\end{array}$ & $\begin{array}{c}\text { Number } \\
(\%) \text { of } \\
\text { BHs }\end{array}$ & $\begin{array}{c}\text { Number } \\
(\%) \text { of } \\
\text { GHs/THs }\end{array}$ & $\begin{array}{c}\text { Number } \\
(\%) \text { of } \\
\text { Total HCI }\end{array}$ \\
\hline Ampa & & $(2.6 \%)$ & $4(7807)$ & & $34(5.0 \%)$ \\
\hline A'pura & $15(5.3 \%)$ & $20(5.9 \%)$ & $5(9.8 \%)$ & $0(0.0 \%)$ & $40(5.9 \%)$ \\
\hline Badulla & $17(6.0 \%)$ & $41(12.1 \%)$ & $3(5.9 \%)$ & $1(10.0 \%)$ & $62(9.1 \%)$ \\
\hline Batticaloa & $0(0.0 \%)$ & $17(5.0 \%)$ & $4(7.8 \%)$ & $1(10.0 \%)$ & $22(3.2 \%)$ \\
\hline Colombo & $12(4.3 \%)$ & $7(2.1 \%)$ & $0(0.0 \%)$ & $0(0.0 \%)$ & $19(2.8 \%)$ \\
\hline Galle & $18(6.4 \%)$ & $14(4.1 \%)$ & $1(2.0 \%)$ & $0(0.0 \%)$ & $33(4.8 \%)$ \\
\hline Gampaha & $13(4.6 \%)$ & $1(0.3 \%)$ & $1(2.0 \%)$ & $2(20.0 \%)$ & $17(2.5 \%)$ \\
\hline H'tota & $12(4.3 \%)$ & $18(5.3 \%)$ & $3(5.9 \%)$ & $1(10.0 \%)$ & $34(5.0 \%)$ \\
\hline Jaffna & $6(2.1 \%)$ & $16(4.7 \%)$ & $3(5.9 \%)$ & $0(0.0 \%)$ & $25(3.7 \%)$ \\
\hline Kalmunai & $0(0.0 \%)$ & $5(1.5 \%)$ & $4(7.8 \%)$ & $0(0.0 \%)$ & $9(1.3 \%)$ \\
\hline Kalutara & $(0.0 \%)$ & $11(3.2 \%)$ & $0(0.0 \%)$ & $1(10.0 \%)$ & $12(1.8 \%)$ \\
\hline Kandy & $19(6.8 \%)$ & $36(10.6 \%)$ & $0(0.0 \%)$ & $0(0.0 \%)$ & $55(8.1 \%)$ \\
\hline Kegalle & $24(8.5 \%)$ & $11(3.2 \%)$ & $2(3.9 \%)$ & $1(10.0 \%)$ & $38(5.6 \%)$ \\
\hline Kilinoc & $1(0.4 \%)$ & $8(2.4 \%)$ & $0(0.0 \%)$ & $1(10.0 \%)$ & $10(1.5 \%)$ \\
\hline Kurunegala & $21(7.5 \%)$ & $16(4.7 \%)$ & $0(0.0 \%)$ & $0(0.0 \%)$ & $37(5.4 \%)$ \\
\hline Mannar & $11(3.9 \%)$ & $12(3.5 \%)$ & $1(2.0 \%)$ & $0(0.0 \%)$ & $24(3.5 \%)$ \\
\hline Matale & $14(5.0 \%)$ & $21(6.2 \%)$ & $1(2.0 \%)$ & $1(10.0 \%)$ & $37(5.4 \%)$ \\
\hline Matara & $17(6.0 \%)$ & $10(2.9 \%)$ & $2(3.9 \%)$ & $0(0.0 \%)$ & $29(4.3 \%)$ \\
\hline & $9(3.2 \%)$ & $15(4.4 \%)$ & $3(5.9 \%)$ & $0(0.0 \%)$ & $27(4.0 \%)$ \\
\hline Mullaitivu & $4(1.4 \%)$ & $5(1.5 \%)$ & & $0(0.0 \%)$ & $11(1.6 \%)$ \\
\hline N'Eliya & $5(1.8 \%)$ & $2(0.6 \%)$ & $0(0.0 \%$ & $0(0.0 \%)$ & $7(1.0 \%)$ \\
\hline P'nnaruwa & $6(2.1 \%)$ & $6(1.8 \%)$ & $2(3.9 \%)$ & $0(0.0 \%)$ & $14(2.1 \%)$ \\
\hline Puttalam & $21(7.5 \%)$ & $14(4.1 \%)$ & $4(7.8 \%)$ & $0(0.0 \%)$ & $39(5.7 \%)$ \\
\hline Ratnapura & $4(1.4 \%)$ & $7(2.1 \%)$ & $3(5.9 \%)$ & $0(0.0 \%)$ & $14(2.1 \%)$ \\
\hline T'malee & $10(3.6 \%)$ & $10(2.9 \%)$ & $2(3.9 \%)$ & $0(0.0 \%)$ & $22(3.2 \%)$ \\
\hline Vavuniya & $1(0.4 \%)$ & $8(2.4 \%)$ & $1(2.0 \%)$ & $1(10.0 \%)$ & $11(1.6 \%)$ \\
\hline
\end{tabular}

\section{RESULTS}


institutions from all the health district of Sri Lanka has participated at this study.

Directorate of NCD of the Ministry of Health as the national focal point to prevention and control of NCDs had provided a guideline on measures to be taken to prevent Covid-19 infection when medical clinics are being conducted. The implementation of the guideline had been further strengthened by conducting series of on-line TOT programmes of district level focal points; MO-NCD. This country wide survey was conducted as a follow up mechanism to provision of guidance and training. These findings would be helpful in assessing the success of implementation of the guideline and to identify the gaps for further improvements.

When this survey was conducted, steps were taken to minimize information bias by using a judgmental validity ensured questionnaire. Furthermore, MO-NCD had assessed random $10 \%$ of the healthcare intuitions who had responded in this survey. This measure has further strengthened the validity of the results of this survey.

Application of a triage system to identify Covid-19 suspicious patients prior to reaching medical clinics is particularly important for ensuring the safety of the other patients as well as the healthcare staff. This practice was found to be in place in nearly $60 \%$ of HIs. Most of the HIs (Nearly $70 \%$ ) follow Covid19 preventive measures especially with regard to reduce overcrowding of clinic patients. This would be helpful in provision of services to the patients without an interruption.

Monitoring of blood pressure and blood sugar levels of the clinics attendees is essential for clinical management of NCD patients. Mechanisms should be established to measure these parameters with minimum infection risk to both healthcare staff as well as the patient. Also, availability of suitable equipment to carry out such activities is instrumental. It is admirable to see, measures had been taken to check essential parameters such as blood pressure and capillary blood sugar adhering to safety precautions in majority $(>70 \%)$ of the HIs.

It is notable that availability of modern facilities to ensure Covid-19 safety was found to be in lower levels in the HIs. This was reflected by the non-availability of telemedicine systems $(<20 \%)$ for patient consultations as well as non-availability of digital blood pressure apparatus $(<35 \%)$ in majority of healthcare intuitions.

One of the methods adopted by the Ministry of Health to provide continuous supply of the drugs to their patients with NCDs was to send drugs via the Government Postal Service. This method was used to minimize patients attending HIs, reduce their mobility and the probability of acquainting Covid-19 infection. But it was noted that majority of primary care intuitions did not prefer this system in contrast to secondary and tertiary care institutions. The main reason behind this finding would be primary care hospitals cater to patients who live in close proximity in contrast to secondary/ tertiary care hospitals of which receive patients residing in distant places.

In view of provision of services to Patients with NCD by medical clinics without an interruption, it is important to follow Covid-19 prevention measures by all the HIs. These findings can be used by the Ministry of Health to identify HIs that do not follow the safety measures and empower them including provision of modern equipment as highlighted by this survey. The findings of this survey will also enlighten the Ministry of Health not to take blanket decision such as provision of drugs via the Government Postal Services for all patients but identify the HIs that need such service prior to such decisions. Replication of similar survey in regular intervals will be helpful in identification of sustainability of measures taken, improvements made and further gaps to be rectified.

\section{CONCLUSION}

Majority of the healthcare institutions throughout the country are practicing Covid-19 safety measures when they conduct medical clinics. Use of modern technology to further strengthen safety measures by healthcare institutions, need to be encouraged.

\section{ACKNOWLEDGMENT}

The support given by all the staff of the Directorate of NCD, Ministry of Health, Medical Officers of NCD at district level and heads of the healthcare institutions who participated at this study is acknowledged.

\section{REFERENCES}

Mallawaarachchi, DS Virginie, Shiranee C. Wickremasinghe, Lakshmi C. Somatunga, Vithanage TSK Siriwardena, and Nalika S. Gunawardena. 2016. 'Healthy Lifestyle Centres: A Service for Screening Non-communicable Diseases through Primary Health-Care Institutions in Sri Lanka'. WHO South-East Asia Journal of Public Health 5(2):8995.

Ministry of Health. 2010. 'The National Policy and Strategic Framework for Prevention and Control of Chronic NonCommunicable Diseases'.

Ministry of Health. 2018. 'Annual Health Bulletin'.

Ministry of Health. 2020. 'SUMMARY OF GOVERNMENT HOSPITALS'.

Senaratne, R., and S. Mendis. 2019. 'Prevention and Control of Noncommunicable Diseases: Think Globally, Act Locally; Lessons from Sri Lanka'.

World Health Organization. 2015. 'Non Communicable Disease Risk Factors: STEPS Survey Sri Lanka'.

World Health Organization. 2020a. 'Noncommunicable Diseases: Campaign for Action-Meeting the NCD Targets. Know the NCD Targets'.

World Health Organization. 2020b. 'Towards A New New Normal : Nationwide COVID-19 Prevention Campaign'.

World Health Organization. 2021. 'Sri Lanka|Covid19 |coronavirus|WHO'. 


\section{AUTHORS}

First Author - Vindya Kumarapeli, MBBS, MSc, MD,

Directorate of Non-Communicable Diseases, Ministry of

Health, Sri Lanka. E mail address- vindyalk@yahoo.com

Second Author - Sinha De Silva, MBBS, MSc, MD,

Postgraduate Institute of Medicine, University of Colombo, Sri

Lanka. E mail address- sinha.dhanushka@gmail.com

Third Author: Dhanushka Abeygunathilaka MBBS, MSc Directorate of Non-Communicable Diseases, Ministry of Health, Sri Lanka. E mail address: danu.abey@yahoo.com

Fourth Author: Nimani de Lanerolle MBBS MSc

Directorate of Non-Communicable Diseases, Ministry of Health, Sri Lanka. E mail address: nimani.del.b@gmail.com

Fifth Author: Casthuri Kandasamy MBBS

Directorate of Non-Communicable Diseases, Ministry of Health, Sri Lanka. E mail address: casthuri12@ gmail.com

Sixth Author: Uthpala Muhandiram MBBS

Directorate of Non-Communicable Diseases, Ministry of Health, Sri Lanka. E mail address: uthpala.muhandiram@gmail.com

Seventh Author: Chithramali Rodrigo MBBS MSc MD Directorate of Non-Communicable Diseases, Ministry of Health, Sri Lanka. E mail address: mal_has@yahoo.com

Correspondence Author - Sinha De Silva, MBBS, MSc, MD, Postgraduate Institute of Medicine, University of Colombo, Sri Lanka. E mail address- sinha.dhanushka@gmail.com 
International Journal of Scientific and Research Publications, Volume 11, Issue 6, June 2021

This publication is licensed under Creative Commons Attribution CC BY. 